\title{
IQ Classification via Brainwave Features: Review on Artificial Intelligence Techniques
}

\author{
Aisyah Hartini Jahidin, Mohd Nasir Taib, Nooritawati Md Tahir, Megat Syahirul Amin Megat Ali \\ Faculty of Electrical Engineering, Universiti Teknologi MARA, Malaysia
}

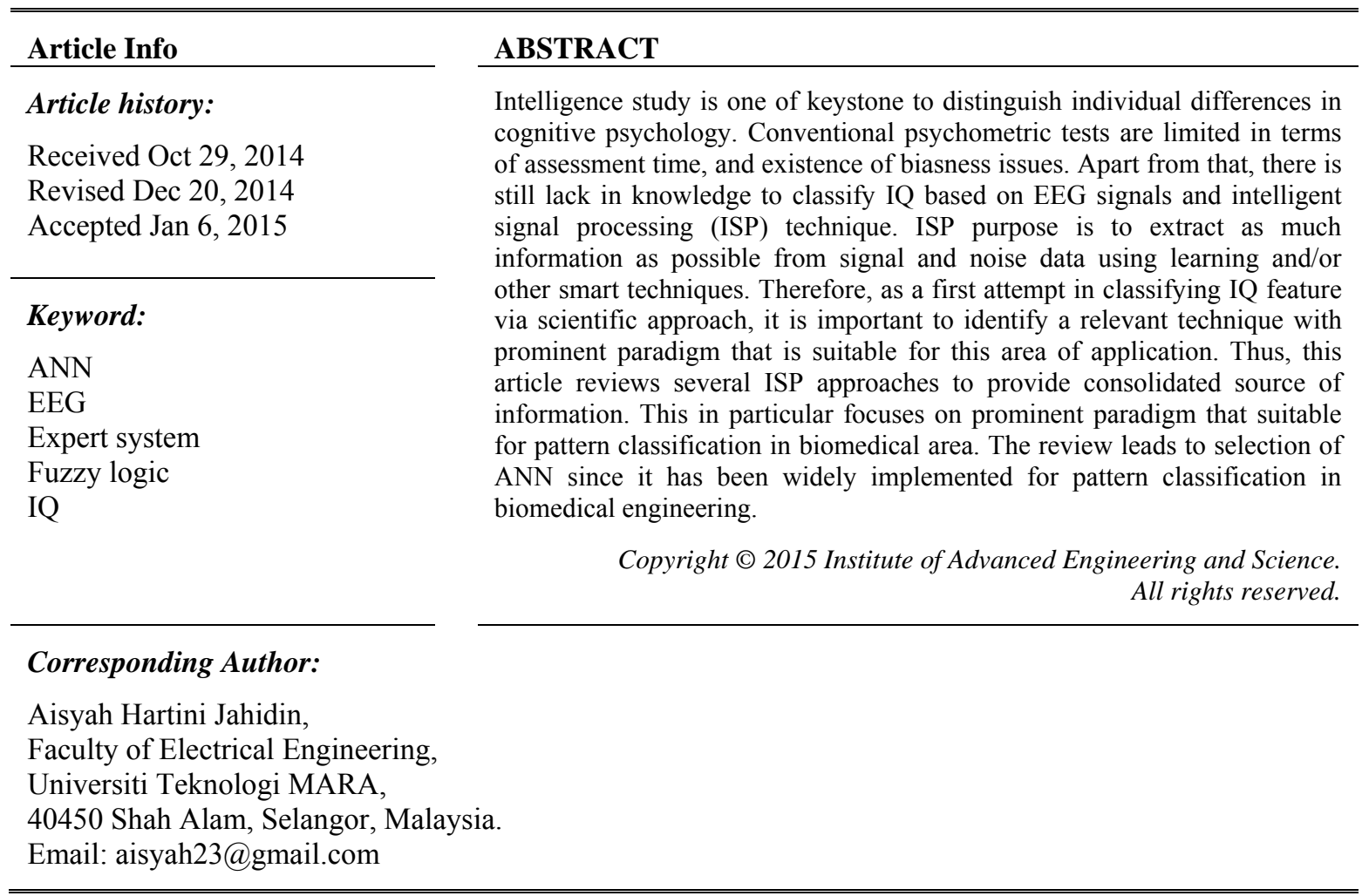

\section{INTRODUCTION}

Cognitive ability is a sub-division of human potential which refers to individual's characteristic approach in information processing. This has been well-established within the domain of human intelligence and is strictly related to intelligence quotient (IQ). To date, IQ is assessable using conventional methods such as Stanford-Binet Intelligence Scales [1], Raven's Progressive Matrices [2], and Wechsler Intelligence Scales [3], which can then be quantified for evaluation of mental performance. A drawback to these type of assessment are that it is relatively insensitive to individual understanding in answering the psychometric tests. Moreover, there would be biasness issue that is unique to each of the assessment batteries [2, 4]. Certainly, EEG has become increasingly important as it can record vast amounts of complex neuronal activity from the human brain. Thus, the qualitative information can be overcome with quantitative measurement provided by the EEG.

In general, EEG can be categorized into primary and secondary signals. A primary EEG can be observed and interpreted directly during the EEG recording. These signals have been utilized extensively to assist clinicians in diagnosing acute paediatric encephalopathy [5], anaesthesia [6], stroke [7], schizophrenia [8], and dementias or Alzheimer [9]. Under severe cases, it is also used to ascertain brain death [10]. Meanwhile, the secondary EEG is used for more sophisticated applications. This however, would require complex data processing approaches for signal manipulation. The secondary EEG have been implemented in person recognition [11], and brain-computer interface [12], as well as investigation on neurophysiological correlates with psychophysiology, which normally includes emotion recognition studies [13] and its effects 
from external stimulus [14]. Other application of EEG can also be related to cognitive abilities such as intelligence [15] and learning style [16].

The features extracted from raw EEG signals without losing its original content are crucial in order to distinguish and classify brain activity effectively. This would enable correlation of parameters with the neuropsychological functioning of the brain. With the aid of various signal processing approaches, characterisations of brainwave features in the past have taken numerous approaches under a broad perspective of EEG studies [17-19]. Such valuable information obtained through innovative signal processing is commonly incorporated with the use of intelligent classifiers and hence, result in the conception of intelligent signal processing (ISP) technique. The approach refers to the implementation of model-free techniques for feature extraction and modelling purposes [20]. These would further contribute to the enhancement of knowledge and lead to a wider range multidisciplinary applications. Certainly, this presents an excellent opportunity to advance the research in relating EEG with IQ via ISP.

Currently, there is a variety of artificial intelligence (AI) techiques [21-24] that could be incorporated for IQ classification via the brainwave features. In order to justify the selection of a particular method, the paper attempts to provide a general overview and applications of established techniques, which are expert system, genetic algorithm, fuzzy logic and artificial neural network (ANN) [21-24]. The discussion then focuses on selection of ANN as suitable ISP method for classification of IQ index based on EEG.

\section{ESTABLISHED INTELLIGENT SIGNAL PROCESSING APPROACHES}

Throughout the years, pattern recognition and classification has been made possible via ISP that specifically focuses on analyzing and modelling of complex data. The aim of ISP is to extract as much information as possible from signal and noise data using dedicated learning techniques [25]. ISP differs fundamentally from the classical approach of statistical signal processing in that the input-output behaviour of a complex system is modelled using intelligent or model-free techniques, rather than relying on the limitations of mathematical models [20]. To achieve such goals, numerous methods can be utilised; each having its own unique advantages and drawbacks. Therefore, it is important to identify a particular ISP technique that could meet the specifications required for modelling the relationship between IQ and brainwave features.

There are wide varieties of ISP techniques currently available. However, this paper will only focus on techniques most commonly found in the literature. These comprise of expert systems, genetic algorithms, fuzzy logic and ANN. It is noted that the methods originate from human-related phenomena and an offspring of broader discipline known as AI. In general, the techniques exhibit similar characteristics of simple computational stages, and often complemented by repetitive learning cycle [26].

It has been implemented in diverse areas, such as science [27], engineering [27, 28], agriculture [27, 29-33], medical [27, 34-41], biomedical [34, 42, 43], computer science [27], and financial [44, 45]. The application paradigms include control, design, diagnosis, instruction, interpretation, monitoring, planning, pattern classification, prescription, prediction, selection, scheduling, maintenance and targeting, optimisation, identification, clustering and feature extractuin [27-32, 34, 35, 37-39, 44-78]. Table 1 summarises each ISP approach with the respective application paradigms. 
Table 1. Summary of ISP Technique and Application Paradigms

\begin{tabular}{|c|c|c|}
\hline Techniques & Application Paradigms & Areas \\
\hline Expert System & $\begin{array}{c}\text { control [27, 57], design [27], prescription [27], } \\
\text { diagnosis [27, 28, 31, 34-37, 56, 57], sorting [29], } \\
\text { identification [30], instruction, interpretation, } \\
\text { monitoring [38, 57], selection [44], managing [45], } \\
\text { planning [59], classification [32], prediction [63] }\end{array}$ & $\begin{array}{l}\text { chemistry [27], geology [27], space technology [27], } \\
\text { electric railway [28], egg grading [29], plant } \\
\text { protection in pepper [30], fish disease diagnosis [31], } \\
\text { pollen grains identificaition [32], computer networks } \\
\text { 43], stock exchange [44], finance management [45], } \\
\text { health [56], industrial [57], drug metabolism [63]. }\end{array}$ \\
\hline Fuzzy Logic & $\begin{array}{c}\text { Control }[75,76,82-84] \text {, decision making }[60], \\
\text { monitoring[39], diagnosis }[40] \text {, identification }[85], \\
\text { pattern recognition/classification }[40,42,76]\end{array}$ & $\begin{array}{c}\text { robotic [84], industrial (automotive) [82], power [83], } \\
\text { geoscience [86], instrumentation [87], stock trading } \\
\text { [60], typhoid fever [40], multifunctional prosthesis } \\
\text { control [42]. }\end{array}$ \\
\hline
\end{tabular}

Expert system is knowledge-based algorithm that emulates the behaviour of human experts in terms of thought and reasoning process [98]. The expert systems can designed as a problem-solving ability model, which involves knowledge, reasoning, conclusion and explanations similar to human expert in order to analyse and solve complex problems [27]. The first expert system was developed in the mid-1960s [21], but its application proliferated in the 1980s [27, 99]. The technique is suitable for closed-system applications for which inputs are literal and precise, leading to logical outputs [98]. Throughout the years, its implementation is mostly intended for diagnosis purposes [27]. Expert systems have a profound application in health diagnostic systems [34, 36, 38, 39, 59], which interpret medical test results [27].

Conversely, genetic algorithm is a solution searching technique, which is rooted in the ideas of evolution process and natural population genetics [74]. The technique that was conceptualized by John Holland in the 1960s, has driven the interest in heuristic search algorithms with foundations in natural and physical processes [79]. Its most prominent implementation is in optimization [68-71, 73, 74]. Consequently, genetic algorithm is most successful in solving problems that are related to characterization in physical sciences [74]. Another ISP technique, the fuzzy logic was founded in 1965 by Lofti Zadeh [23]. The concept was adopted from human thinking and much resembles the natural language compared to the traditional logical systems [75]. Within the next two decades, fuzzy logic has been widely implemented to solve problems from decision-making theory. The technique is most successfully applied in control problems [64, $75,76,82-84]$. The system however, is not capable of learning [100]. Hence, its implementation in the area of pattern recognition is still limited. To minimize such drawback, fuzzy logic will need to be integrated with other ISP techniques [42, 87].

Meanwhile, ANN is a non-linear artificial intelligence approach that is inspired by the working of biological neurons in the brain [101]. The technique that was introduced in the 1940s has recently seen a sharp increase in its implementation [24]. ANN has been an alternative to the traditional statistical modelling techniques in various scientific disciplines [102]. Its main advantage lies in its ability to learn and generalize solutions for complex problems [101]. Hence, the method is particularly useful for solving a probem for which large amount of data is involved, but with unknown inter-relationship [102]. It can approximate the non-linear relationship between the input variables and the output of a sophisticated system [103]. Implementation of the ANN can be mostly found in biomedical applications [46, 47, 52]. Moreover, it was also discovered that ANN has been very successful when integrated with innovative signal processing approach for pattern recognition purposes [88-91, 104]. 


\section{COMPARATIVE ANALYSIS}

Table 2 summarizes on the selection criterias for the comparative analysis. The selection criteria include capabilities to generalize solution for complex problems, to self-learn, analyze and model non-linear relationships, as well as its primary purpose of implementation.

Table 2. Selection Criterias

\begin{tabular}{|c|c|c|c|c|c|}
\hline & Criterias & ES & GA & FL & ANN \\
\hline 1 & $\begin{array}{l}\text { Generalize Solution for Complex } \\
\text { Problems }\end{array}$ & Yes & Yes & No & Yes \\
\hline 2 & Self-learning Capability & No & Yes & No & Yes \\
\hline 3 & $\begin{array}{l}\text { Analyze and Model Non-linear } \\
\text { Relationships }\end{array}$ & No & No & No & Yes \\
\hline 4 & Purpose of Implementation & Diagnosis & Optimization & Decision-making & Pattern recognition \\
\hline
\end{tabular}

Up to this point, it has been identified that ANN is the most suitable approach to be implemented for IQ modelling via the EEG. This is attributed by its previous successes as a robust modelling technique in biomedical applications, particularly for pattern recognition and classification. Thus, the following section will further elaborate on the important aspects of ANN which include its most popular architecture.

\subsection{Artificial Neural Network}

ANN was pioneered by McCulloch and Pitts in the 1940s. Later, the perceptron convergence theorem has been introduced by Rosenblatt in the 1960s [101]. Despite this, the theory was still having its limitations, which resulted in slowdown of the research area. However, the enthusiasm resurged in 1982 with the introduction of back-propagation learning algorithm by Werbos for the multilayer perceptron network. In 1986 [24], it was further popularized by Rumelhart. Ever since, the use of ANN has seen a steady growth with applications spaning across a wide range of problem domains as previously mention in Table 1.

The multilayer perceptron is currently the most established supervised neural network model for practical applications in solving diverse and complex problems [91]. As an intelligent technique, the multilayer perceptron has been widely used for optimisation, modelling, prediction and function approximation purposes [105]. However, it has also been successfully applied to a variety of pattern recognition and classification problems [54, 55]. Such applications include disease recognition [77], physiological analysis and modeling [46], cancer detection and classification [47], modelling of heart disease recognition [106], diagnosis of coronary artery disease [49], and other related studies [52, 89].

\subsection{Integration of Artificial Neural Network and EEG for IQ Classification}

Implementation of ANN in biomedical application has been observed in signal compression, enhancement and interpretation [89]. The proposed research on IQ classification via brainwave features fall within the domain of signal interpretation, whereby the pattern of EEG sub-band features will be recognized through a learning process and later classified into discrete IQ levels [107]. An uncompromising advantage of ANN also lies in the ability to cross-correlate data correctly from unknown relationships.

ANN has certainly established itself as the most successfully modelling technique for biomedical applications [52, 108], particularly in the area of pattern recognition [54]. Over the years, several types of ANN have been developed, each with unique properties that make them more suitable for certain task over the others. The network architecture varies in terms of structure, activation function and learning algorithm. In general, the ANN can be implemented in supervised and unsupervised learning modes [109]. Under the former setting, the network will have to recognize the pattern only from the input variables. Conversely, the later will allow the network to learn by recognizing the relationship between the input variables and the output. Hence in our proposed work, the network will be implemented in supervised learning settings whereby the EEG features will be assigned as the inputs and the distinct IQ levels as the actual output. This would allow the network to be trained by confirming its performance to the provided output.

\section{CONCLUSION}

Among various ISP approaches, the ANN is perceived as a significant technique for pattern recognition and classification through its modelling capabilities. Its implementation has extended to a wide range of biomedical applications. Thus, ANN is considered as the most suitable method to model the IQ from brainwave features. 


\section{ACKNOWLEDGEMENTS}

Authors extend their appreciation to the Ministry of Education, Malaysia and Universiti Teknologi MARA for the financial support through the Fundamental Research Grant Scheme (600-RMI/FRGS 5/3 (72/2012)) and MyPhD scholarship.

\section{REFERENCES}

[1] S.B.I. Scales, "History of the Stanford-Binet Intelligence Scales: Content and Psychometrics," 2003.

[2] J. Raven, "The Raven's progressive matrices: change and stability over culture and time," Cognitive psychology, vol. 41, pp. 1-48, 2000.

[3] D. Wechsler, "Wechsler adult intelligence scale-Fourth Edition (WAIS-IV)," San Antonio, TX: NCS Pearson, 2008.

[4] D.F. Lohman, et al., "Identifying Academically Gifted English-Language Learners Using Nonverbal Tests: A Comparison of the Raven, NNAT, and CogAT," Gifted Child Quarterly, vol. 52, pp. 275-296, October 1, 2008 2008.

[5] E. Hussain and D. Nordli, "EEG Patterns in Acute Pediatric Encephalopathies," Journal of clinical neurophysiology: official publication of the American Electroencephalographic Society, vol. 30, pp. 539-544, 2013.

[6] V.V. Moca, et al., "EEG under anesthesia--feature extraction with TESPAR," Computer Methods and Programs in Biomedicine, vol. 95, pp. 191-202, Sep 2009.

[7] M.J. van Putten and D.L. Tavy, "Continuous quantitative EEG monitoring in hemispheric stroke patients using the brain symmetry index," Stroke, vol. 35, pp. 2489-92, Nov 2004.

[8] M. Koukkou, et al., "An EEG approach to the neurodevelopmental hypothesis of schizophrenia studying schizophrenics, normal controls and adolescents," Journal of Psychiatric Research, vol. 34, pp. 57-73, 2000.

[9] C.E. Jackson and P.J. Snyder, "Electroencephalography and event-related potentials as biomarkers of mild cognitive impairment and mild Alzheimer's disease," Alzheimer's \& Dementia, vol. 4, pp. S137-S143, 2008.

[10] D.M. Murray, et al., "Early EEG findings in hypoxic-ischemic encephalopathy predict outcomes at 2 years," Pediatrics, vol. 124, pp. e459-67, Sep 2009.

[11] P. Campisi, et al., "EEG for Automatic Person Recognition," Computer, vol. 45, pp. 87-89, 2012.

[12] S. Sun, "Extreme energy difference for feature extraction of EEG signals," Expert Systems with Applications, vol. 37 , pp. 4350-4357, 2010

[13] N. Sharma and T. Gedeon, "Objective measures, sensors and computational techniques for stress recognition and classification: a survey," Computer Methods and Programs in Biomedicine, vol. 108, pp. 1287-301, Dec 2012.

[14] T. Baumgartner, et al., "From emotion perception to emotion experience: Emotions evoked by pictures and classical music," International Journal of Psychophysiology, vol. 60, pp. 34-43, 2006.

[15] A.H. Jahidin, et al., "Brainwave sub-band power ratio characteristics in intelligence assessment," in IEEE Control and System Graduate Research Colloquium (ICSGRC), 2012, pp. 318-321.

[16] M.S.A. Megat Ali, et al., "Learning Style Classification via EEG Subband Spectral Centroid Frequency Features," International Journal of Electrical and Computer Engineering (IJECE), vol. 4, pp. 931-938, 2014.

[17] S. Sanei and J.A. Chambers, EEG signal processing: Wiley-Interscience, 2008.

[18] S. Xie and S. Krishnan, "Wavelet-based sparse functional linear model with applications to EEGs seizure detection and epilepsy diagnosis," Medical \& Biological Engineering \& Computing, vol. 51, pp. 49-60, 2013/02/01 2013.

[19] G. Chen, "Automatic EEG seizure detection using dual-tree complex wavelet-Fourier features," Expert Systems with Applications, vol. 41, pp. 2391-2394, 2014.

[20] S.S. Haykin and B. Kosko, Intelligent signal processing: Wiley-IEEE Press, 2001.

[21] L. Shu-Hsien, "Expert system methodologies and applications - a decade review from 1995 to 2004," Expert Systems with Applications, vol. 28, pp. 93-103, 2005.

[22] J.F. Frenzel, "Genetic algorithms," Potentials, IEEE, vol. 12, pp. 21-24, 1993.

[23] L.A. Zadeh, "Fuzzy sets," Information and control, vol. 8, pp. 338-353, 1965.

[24] A.K. Jain, et al., "Artificial neural networks: A tutorial," IEEE computer, vol. 29, pp. 31-44, 1996.

[25] S. Haykin and B. Kosko, "Special Issue On Intelligent Signal Processing," Proceedings of the IEEE, vol. 86, pp. 2119-2120, 1998.

[26] K.T. Yang, "Artificial Neural Networks (ANNs): A New Paradigm for Thermal Science and Engineering," Journal of Heat Transfer, vol. 130, p. 093001, 2008.

[27] J. Durkin, "Research review: Application of expert systems in the sciences," Ohio Journal of Science, vol. 90, pp. 171-179, 1990.

[28] Z. Liu and Z. Han, "Fault diagnosis of electric railway traction substation with model-based relation guiding algorithm," Expert Systems with Applications, vol. 41, pp. 1730-1741, 2014.

[29] V. Patel, et al., "Development and evaluation of an expert system for egg sorting," Computers and Electronics in Agriculture, vol. 20, pp. 97-116, 1998.

[30] L. Gonzalez-Diaz, et al., "Expert system for integrated plant protection in pepper (Capsicum annuun L.)," Expert Systems with Applications, vol. 36, pp. 8975-8979, 2009.

[31] D. Li, et al., "Fish-Expert: a web-based expert system for fish disease diagnosis," Expert Systems with Applications, vol. 23, pp. 311-320, 2002. 
[32] Y. Kaya, et al., "An expert classification system of pollen of Onopordum using a rough set approach," Review of Palaeobotany and Palynology, vol. 189, pp. 50-56, 2013.

[33] M. Safa and S. Samarasinghe, "Modelling fuel consumption in wheat production using artificial neural networks," Energy, vol. 49, pp. 337-343, 2013.

[34] J. Nahar, et al., "Computational intelligence for microarray data and biomedical image analysis for the early diagnosis of breast cancer," Expert Systems with Applications, vol. 39, pp. 12371-12377, 2012.

[35] G. Sardana, et al., "Emerging biomarkers for the diagnosis and prognosis of prostate cancer," Clinical chemistry (Baltimore, Md.), vol. 54, pp. 1951-60, 2008.

[36] F. Basciftci and A. Eldem, "Using reduced rule base with Expert System for the diagnosis of disease in hypertension," Medical \& Biological Engineering \& Computing, vol. 51, pp. 1287-93, Dec 2013.

[37] P. Baptista, et al., "Gold nanoparticles for the development of clinical diagnosis methods," Analytical and Bioanalytical Chemistry, vol. 391, pp. 943-50, Jun 2008.

[38] E. Seto, et al., "Developing healthcare rule-based expert systems: case study of a heart failure telemonitoring system," Int J Med Inform, vol. 81, pp. 556-65, Aug 2012.

[39] M. Mansoor Baig, et al., "Fuzzy logic based anaesthesia monitoring systems for the detection of absolute hypovolaemia," Computers in Biology and Medicine, vol. 43, pp. 683-92, Jul 2013.

[40] O.W. Samuel, et al., "A web based decision support system driven by fuzzy logic for the diagnosis of typhoid fever," Expert Systems with Applications, vol. 40, pp. 4164-4171, 2013.

[41] A.T. Azar, "Fast neural network learning algorithms for medical applications," Neural Computing and Applications, vol. 23, pp. 1019-1034, 2012.

[42] A.B. Ajiboye and R.F. Weir, "A heuristic fuzzy logic approach to EMG pattern recognition for multifunctional prosthesis control," Neural Systems and Rehabilitation Engineering, IEEE Transactions on, vol. 13, pp. 280-291, 2005.

[43] M. Ronzhina, et al., "Sleep scoring using artificial neural networks," Sleep Med Rev, vol. 16, pp. 251-63, Jun 2012.

[44] P. Xidonas, et al., "On the selection of equity securities: An expert systems methodology and an application on the Athens Stock Exchange," Expert Systems with Applications, vol. 36, pp. 11966-11980, 2009.

[45] W. Shiue, et al., "A frame knowledge system for managing financial decision knowledge," Expert Systems with Applications, vol. 35, pp. 1068-1079, 2008.

[46] M. Duta, et al., "Neural network analysis of the mastoid EEG for the assessment of vigilance," International Journal of Human-Computer Interaction, vol. 17, pp. 171-195, 2004/06/01 2004.

[47] J. Khan, et al., "Classification and diagnostic prediction of cancers using gene expression profiling and artificial neural networks," Nature medicine, vol. 7, pp. 673-679, 2001.

[48] J. Kuruvilla and K. Gunavathi, "Lung cancer classification using neural networks for CT images," Computer Methods and Programs in Biomedicine, vol. 113, pp. 202-9, Jan 2014.

[49] R. Alizadehsani, et al., "A data mining approach for diagnosis of coronary artery disease," Computer Methods and Programs in Biomedicine, vol. 111, pp. 52-61, Jul 2013.

[50] C. Zecchin, et al., "Jump neural network for online short-time prediction of blood glucose from continuous monitoring sensors and meal information," Computer Methods and Programs in Biomedicine, vol. 113, pp. 144-52, Jan 2014

[51] A. Kupusinac, et al., "Predicting body fat percentage based on gender, age and BMI by using artificial neural networks," Computer Methods and Programs in Biomedicine, vol. 113, pp. 610-619, Feb 2014.

[52] P.J. Lisboa, "A review of evidence of health benefit from artificial neural networks in medical intervention," Neural networks, vol. 15, pp. 11-39, 2002.

[53] E. Poletti, et al., "A modular framework for the automatic classification of chromosomes in Q-band images," Computer Methods and Programs in Biomedicine, vol. 105, pp. 120-130, 2012.

[54] J.L. Amaral, et al., "An improved method of early diagnosis of smoking-induced respiratory changes using machine learning algorithms," Computer Methods and Programs in Biomedicine, vol. 112, pp. 441-54, Dec 2013.

[55] S. İçer, et al., "Comparison of multilayer perceptron training algorithms for portal venous doppler signals in the cirrhosis disease," Expert Systems with Applications, vol. 31, pp. 406-413, 2006.

[56] Y. Chen, et al., "Constructing a nutrition diagnosis expert system," Expert Systems with Applications, vol. 39, pp. 2132-2156, 2012.

[57] V. Uraikul, et al., "Artificial intelligence for monitoring and supervisory control of process systems," Engineering Applications of Artificial Intelligence, vol. 20, pp. 115-131, 2007.

[58] E. Németh, et al., "Prediction-based diagnosis and loss prevention using qualitative multi-scale models," Information Sciences, vol. 177, pp. 1916-1930, 2007.

[59] C.L. Hsu, et al., "A secure IRB system for assisting the development of intelligent medical devices," Expert Systems with Applications, vol. 39, pp. 12512-12521, 2012.

[60] L. Dymova, et al., "A stock trading expert system based on the rule-base evidential reasoning using Level 2 Quotes," Expert Systems with Applications, vol. 39, pp. 7150-7157, 2012.

[61] J.S. Cope, et al., "Reverse engineering expert visual observations: From fixations to the learning of spatial filters with a neural-gas algorithm," Expert Systems with Applications, vol. 40, pp. 6707-6712, 2013.

[62] C. Chen, et al., "An integrated architecture for fault diagnosis and failure prognosis of complex engineering systems," Expert Systems with Applications, vol. 39, pp. 9031-9040, 2012.

[63] A. Long, "Drug metabolism in silico - the knowledge-based expert system approach. Historical perspectives and current strategies," Drug Discov Today Technol, vol. 10, pp. e147-53, Spring 2013. 
[64] D.A. Linkens and H.O. Nyongesa, "Learning systems in intelligent control: an appraisal of fuzzy, neural and genetic algorithm control applications," IEE Proceedings-Control Theory and Applications, vol. 143, pp. 367-386, 1996.

[65] E.S. Hou, et al., "A genetic algorithm for multiprocessor scheduling," Parallel and Distributed Systems, IEEE Transactions on, vol. 5, pp. 113-120, 1994.

[66] J.C. Chen, et al., "Flexible job shop scheduling with parallel machines using Genetic Algorithm and Grouping Genetic Algorithm," Expert Systems with Applications, vol. 39, pp. 10016-10021, 2012.

[67] M. Lee and E.K. Kang, "Termite tunneling feature extraction using genetic algorithm," Soft Computing, vol. 16, pp. 419-425, 2011.

[68] K.S. Tang, et al., "Genetic algorithms and their applications," Signal Processing Magazine, IEEE, vol. 13, pp. 22$37,1996$.

[69] D. Whitley, "A genetic algorithm tutorial," Statistics and computing, vol. 4, pp. 65-85, 1994.

[70] U. Kesgin, "Genetic algorithm and artificial neural network for engine optimisation of efficiency and NOx emission," Fuel, vol. 83, pp. 885-895, 2004.

[71] T. Back, et al., "Evolutionary computation: comments on the history and current state," Evolutionary Computation, IEEE Transactions on vol. 1, pp. 3-17, 1997.

[72] C.F.M. Toledo, et al., "Global optimization using a genetic algorithm with hierarchically structured population," Journal of Computational and Applied Mathematics, vol. 261, pp. 341-351, 2014.

[73] M. Srinivas and L.M. Patnaik, "Genetic algorithms: a survey," Computer, vol. 27, pp. 17-26, 1994.

[74] D.A. Coley, "Genetic algorithms," Contemporary Physics, vol. 37, pp. 145-154, 1996.

[75] C.C. Lee, "Fuzzy logic in control systems: fuzzy logic controller. I," Systems, Man and Cybernetics, IEEE Transactions on, vol. 20, pp. 419-435, 1990.

[76] P. Guillemin, "Fuzzy logic applied to motor control," Industry Applications, IEEE Transactions on, vol. 32, pp. 51$56,1996$.

[77] T. Faisal, et al., "A noninvasive intelligent approach for predicting the risk in dengue patients," Expert Systems with Applications, vol. 37, pp. 2175-2181, 2010.

[78] A. Sotelo, et al., "Identification of epilepsy stages from ECoG using genetic programming classifiers," Computers in Biology and Medicine, vol. 43, pp. 1713-23, Nov 2013.

[79] R. Leardi, "Genetic algorithms in chemistry," Journal of Chromatography A, vol. 1158, pp. 226-33, Jul 272007.

[80] E.S. Moghaddam, "Design of a Printed Quadrifilar-Helical Antenna on a Dielectric Cylinder by Means of a Genetic Algorithm [Antenna Applications Corner]," Antennas and Propagation Magazine, IEEE, vol. 53, pp. 262-268, 2011.

[81] R.O. Ryan and S. Jinjun, "Active vibration control using genetic algorithm-based system identification and positive position feedback," Smart Materials and Structures, vol. 21, p. 055002, 2012.

[82] N.J. Schouten, et al., "Fuzzy logic control for parallel hybrid vehicles," Control Systems Technology, IEEE Transactions on, vol. 10, pp. 460-468, 2002.

[83] C. Cecati, et al., "A Multilevel Inverter for Photovoltaic Systems With Fuzzy Logic Control," Industrial Electronics, IEEE Transactions on, vol. 57, pp. 4115-4125, 2010.

[84] P.M. Aubin, et al., "A Robotic Cadaveric Gait Simulator With Fuzzy Logic Vertical Ground Reaction Force Control," Robotics, IEEE Transactions on, vol. 28, pp. 246-255, 2012.

[85] F. Cismondi, et al., "Reducing unnecessary lab testing in the ICU with artificial intelligence," Int J Med Inform, vol. 82, pp. 345-58, May 2013.

[86] J.A. Giannini and C. Kilgus, "A fuzzy logic technique for correcting climatological ionospheric models," Geoscience and Remote Sensing, IEEE Transactions on, vol. 35, pp. 470-474, 1997.

[87] F. Russo, "Fuzzy systems in instrumentation: fuzzy signal processing," Instrumentation and Measurement, IEEE Transactions on, vol. 45, pp. 683-689, 1996.

[88] R. Kozma, et al., "Advances in neural networks research: an introduction," Neural Networks, vol. 22, pp. 489-90, Jul-Aug 2009.

[89] S. Kara and M. Okandan, "Atrial fibrillation classification with artificial neural networks," Pattern Recognition, vol. 40, pp. 2967-2973, 2007.

[90] R.P. Lippmann, "Pattern classification using neural networks," Communications Magazine, IEEE, vol. 27, pp. 47$50,1989$.

[91] G.P. Zhang, "Neural networks for classification: a survey," Systems, Man, and Cybernetics, Part C: Applications and Reviews, IEEE Transactions on, vol. 30, pp. 451-462, 2000.

[92] E. Sezer, et al., "Employment and Comparison of Different Artificial Neural Networks for Epilepsy Diagnosis from EEG Signals," Journal of Medical Systems, vol. 36, pp. 347-362, 2012/02/01 2012.

[93] K. Methaprayoon, et al., "An integration of ANN wind power estimation into unit commitment considering the forecasting uncertainty," Industry Applications, IEEE Transactions on, vol. 43, pp. 1441-1448, 2007.

[94] E.D. Übeyli and İ. Güler, "Feature extraction from Doppler ultrasound signals for automated diagnostic systems," Computers in Biology and Medicine, vol. 35, pp. 735-764, 2005.

[95] D. Singhal and K.S. Swarup, "Electricity price forecasting using artificial neural networks," International Journal of Electrical Power \& Energy Systems, vol. 33, pp. 550-555, 2011.

[96] B.G. Kermani, et al., "Performance of the Levenberg-Marquardt neural network training method in electronic nose applications," Sensors and Actuators B: Chemical, vol. 110, pp. 13-22, 2005. 
[97] B. He, et al., "Estimating monthly total nitrogen concentration in streams by using artificial neural network," Journal of Environmental Management, vol. 92, pp. 172-177, 2011.

[98] M. Yahia, et al., "Rough neural expert systems," Expert Systems with Applications, vol. 18, pp. 87-99, 2000.

[99] F. Hayes-Roth, "Knowledge-Based Expert Systems," Computer, vol. 17, pp. 263-273, 1984.

[100] D. Chakrborty and N. R. Pal, "Integrated feature analysis and fuzzy rule-based system identification in a neurofuzzy paradigm," Systems, Man, and Cybernetics, Part B: Cybernetics, IEEE Transactions on, vol. 31, pp. 391-400, 2001.

[101] S. Haykin, Neural networks: a comprehensive foundation: Prentice Hall PTR, 1994.

[102] E. Grossi and M. Buscema, "Introduction to artificial neural networks," European Journal of Gastroenterology and Hepatology, vol. 19, pp. 1046-1054, 2007.

[103] M.N. Taib, et al., "Extending the response range of an optical fibre pH sensor using an artificial neural network," Analytica Chimica Acta, vol. 330, pp. 31-40, 1996.

[104] N. Chen, et al., "Edge Detection Based on Biomimetic Pattern Recognition," TELKOMNIKA Indonesian Journal of Electrical Engineering, vol. 12, pp. 6965-6968, 2014.

[105] Y. Sun, et al., "Application of artificial neural networks in the design of controlled release drug delivery systems," Advanced Drug Delivery Reviews, vol. 55, pp. 1201-1215, 2003.

[106] A.E. Zadeh, et al., "Classification of the electrocardiogram signals using supervised classifiers and efficient features," Computer Methods and Programs in Biomedicine, vol. 99, pp. 179-194, 2010.

[107] A.H. Jahidin, et al., "Classification of intelligence quotient via brainwave sub-band power ratio features and artificial neural network," Computer Methods and Programs in Biomedicine, vol. 114, pp. 50-59, 2014.

[108] F. Amato, et al., "Artificial neural networks in medical diagnosis," Journal of Applied Biomedicine, vol. 11, pp. 4758,2013

[109] A.K. Jain, et al., "Statistical pattern recognition: A review," Pattern Analysis and Machine Intelligence, IEEE Transactions on, vol. 22, pp. 4-37, 2000.

\section{BIOGRAPHIES OF AUTHORS}

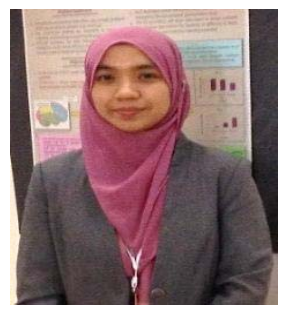

Aisyah Hartini Jahidin obtained the B.Eng (Telecommunication) and M.Eng.Sc (Electrical) from Universiti Malaya, Malaysia. She is currently a postgraduate researcher at the Faculty of Electrical Engineering, Universiti Teknologi MARA, Malaysia. Her main research interests include human intelligence, cognitive ability, EEG and non-linear modelling of brain behavior via intelligent signal processing technique.

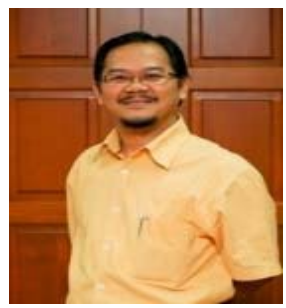

Mohd Nasir Taib obtained the B.Eng (Electrical) from the University of Tasmania, Australia, M.Sc. (Control Systems) from University of Sheffield, and Ph.D. (Control \& Instrumentation) from University of Manchester Institute of Science and Technology, United Kingdom. He is currently a Professor and the Dean of the Faculty of Electrical Engineering, Universiti Teknologi MARA, Malaysia. He is leading an active research group and supervising a pool of researchers in advanced signal processing with applications in control systems and process, biomedical engineering, and nonlinear systems.

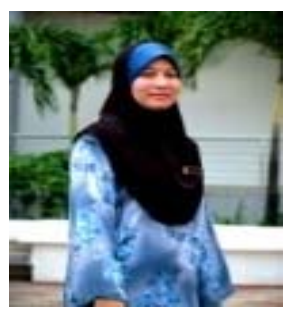

Nooritawati Md Tahir received the B.Eng (Electronics) from the Universiti Teknologi MARA, Malaysia, M.Sc. (Microelectronics \& Telecommunications) from University of Liverpool, United Kingdom, and Ph.D. in Electrical Engineering (Pattern Recognition \& Artificial Intelligence) from Universiti Kebangsaan Malaysia, Malaysia. She is currently an Associate Professor at the Faculty of Electrical Engineering and the Director of Research Innovation Business Unit, Universiti Teknologi MARA, Malaysia. Her research interests include image processing, pattern recognition, computer vision and artificial intelligence.

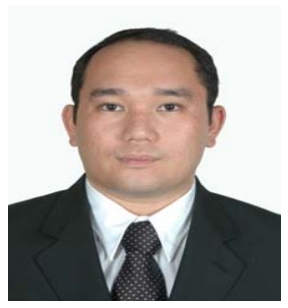

Megat Syahirul Amin Megat Ali received the B.Eng (Biomedical) from Universiti Malaya, Malaysia, and M.Sc. (Biomedical Engineering) from University of Surrey, United Kingdom. He is currently a senior lecturer at the Faculty of Electrical Engineering, Universiti Teknologi MARA, Malaysia. His research interests include EEG and intelligent modelling of brain behavior with application to experiential learning theory. 